\title{
Evaluation of Geometric Quality of Weld Beads in the Joining of Carbon Steel Pipelines with Single Pass
}

\author{
José Eduardo Silveira Leal, Thonson Ferreira Costa, Rosenda Valdés Arencibia \\ Federal Universityof Uberlândia, Avenida João Naves de Ávila, 2121, Campus Santa Mônica, Bloco 5F, CEP 38400-902, Uberlândia- \\ MG, Brazil. \\ Email: zeduardoleal@yahoo.com.br, thonsoncosta@yahoo.com.br, arvaldes@mecanica.ufu.br
}

Received August 2013

\begin{abstract}
This work presents the uncertainty evaluation associated with the measurement of linear parameters that define the weld geometry, specifically the width, using a profile projector, in order to meet the current technical standards. The following steps were proposed and implemented: identification of linear parameters that define the weld geometry; identification and study of variables that affect the measurement of these parameters; the adoption of the mathematical model to estimate the uncertainty; planning and execution of experiments for data collection, calculation of uncertainty and, finally, analysis and discussion of the results. Through the results analysis it was concluded that the weld in overhead position produces the lowest front bead width values and the vertical weld produces the largest width values. The expanded uncertainty values were between $0.016 \mathrm{~mm}$ and $0.075 \mathrm{~mm}$ for all measurements, and the overhead position showed, on average, the highest values.
\end{abstract}

Keywords: Welding; Weld Bead Geometry; Profile Projector; Uncertainty

\section{Introduction}

Welding is undoubtedly the cheapest, most efficient and versatile bonding between materials. Its application is not restricted to manufacturing and service, but extends to the maintenance and repair [1]. Welding is the most important industrial process for metal parts manufacturing [2].

The scope of the welding is practically unrestricted, passing from the feasibility of a metal chair to the most sophisticated spacecraft. The welding is indispensable in the shipbuilding industry (ships, submarines, etc.), mechanical industry (equipment, capital goods, etc.), in the automotive industry (cars, trucks, tractors, etc.) aerospace (satellites, aircraft, spaceships, etc.), construction (steel structures, bridge and buildings), in the nuclear industry (reactors and cooling systems), in the energy industry (transmission cables and turbines) in pressure vessels in petrochemical plants, storage tanks, offshore platforms, in microelectronics, as well as hundreds of other applications [1].

The multidisciplinary knowledge is another welding key feature once the essential requirements are metallurgy, mechanics, electrotechnology, chemistry, physics, materials, quality control, safety, and other factors inherent in industrial production.

In any welded joint sizing, several aspects must be considered, such as: the level of efforts solicitation, the fixing process, the operation difficulty degree, the geometric ratio between bead and welded components, required production, the base material composition, the process automation degree besides the cost involved. However, an appropriate sizing is not enough to ensure the final product quality of welding processes and is essential the development of means and methods to verify the dimensions in order to assess whether they are in accordance with the specified in the project stage [3].

Therefore, welded joints quality control is critical to ensure the final product quality of the welding processes, as well as in the researches developed in the subject. However, for the results of measurements that underlie the mare traceable, measurement systems and calibrated equipment must be used and measurement uncertainty most be evaluated and declared [4].

During the quality control parameters that define the weld bead geometry, templates and gauges are used. Some authors use calipers to measure the weld bead linear parameters [5], while others use the profile projector [6]. Image capture systems are often used associated with computer programs [3] especially in research development.

These measurement systems have operating principles and different constructive characteristics, therefore the 
sources of errors also differ, as well as the necessary mathematical models for measurement uncertainty evaluation $[3,5,7]$.

For these reasons, this article aims to assess the weld beads geometric quality obtained with MIG/MAG derivative short-circuit process (STT-Surface Tension Transfer) in the carbon steel pipelines welding with single pass. For the three forward different conditions: flat $(F)$, vertical $(\mathrm{V})$ and overhead position $(\mathrm{OH})$ (Figure 1).

Further, the measurement of uncertainty evaluation associated with the linear parameters which define the weld bead geometry is shown, specifically the width, using a profile projector. It also presents an analysis of the influence factors which affect the overall uncertainty. This analysis has the expectation of emphasizing the operator training importance during the measurement process.

\section{Testes Experimentais}

Weld beads were obtained using the MIG/MAG derivative process with short circuit (STT-Surface Tension Transfer) the welding of carbon steel pipelines with single pass. The carbon steel pipes have nominal internal diameter $2 \frac{1}{2} 2^{\prime \prime}(63 \mathrm{~mm})$ and a thickness of $5.5 \mathrm{~mm}$. In this study, experiment was carried out on the base materials plates with $75^{\circ}$ groove, $2.0 \mathrm{~mm}$ root-gap and root-face. The contact-tip to workpiece distance (CTWD) was 12 $\mathrm{mm}$ and the electrode wire was used ER 70S-6 with 1.2 $\mathrm{mm}$ diameter and $\mathrm{Ar}+25 \% \mathrm{CO}_{2}$ as shielding gas.

In addition, the weld beads were done in downward progression, with torch oscillation. The travel speed was set to maintain about the same amount of weld material deposited per unit length of weld (WFS/TS constant).

As specific parameters were varied in three levels, the wire feed speed "WFS" in $(2.3 \mathrm{~m} / \mathrm{min}, 2.8 \mathrm{~m} / \mathrm{min}$ and 3.3 $\mathrm{m} / \mathrm{min})$, maintaining constants the peak current " $I_{P}$ " (300 A), the background current " $I_{B}$ ” (80 A) and Tail-out (5).

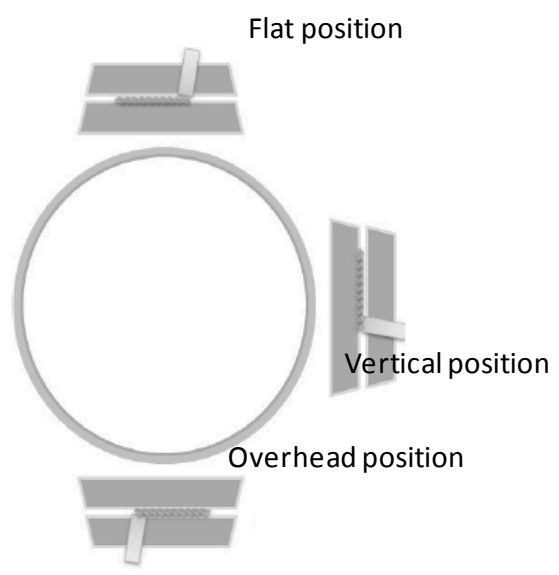

Figure 1. Schematic of pipe weld experiment with different welding position [8].
Table 1 shows the setting parameters and the measured values for average current $\left(I_{A}\right)$, average voltage $\left(U_{A}\right)$ and welding energy input $\left(E_{W}\right)$.

After the welding, specimens were prepared and assembled as shown in Figure 2. These specimens have been previously identified as SD10, SD11 and SD18 and each contains three weld beads, one obtained in the flat (F), vertical (V) and in overhead position (OH).

The front width of each weld bead (Figure 3) was measured three times using a profile projector, model PJ-A3000, manufactured by MITUTOYO (Figure 4) and a $10 \times$ magnifying lens.

Table 1. Measured values for electric current and voltage in the descending process STT.

\begin{tabular}{cccc}
\hline Test & 1(SD10) & 2(SD11) & 3(SD18) \\
\hline WFS [m/min] & 2.3 & 3.3 & 2.8 \\
$I_{B}[\mathrm{~A}]$ & 80 & 80 & 80 \\
$I_{P}[\mathrm{~A}]$ & 300 & 300 & 300 \\
Tail-out & 5 & 5 & 5 \\
$I_{A}[\mathrm{~A}]$ & 120.4 & 146.8 & 133.7 \\
$U_{A}[\mathrm{~V}]$ & 17.2 & 15.4 & 15.2 \\
$E_{W}[\mathrm{~J} / \mathrm{cm}]$ & 172.57 & 125.60 & 135.48 \\
\hline
\end{tabular}

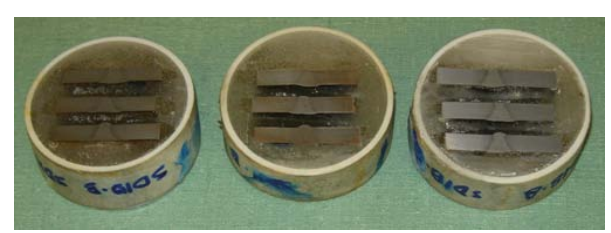

Figure 2. Specimens SD10, SD11 and SD18.

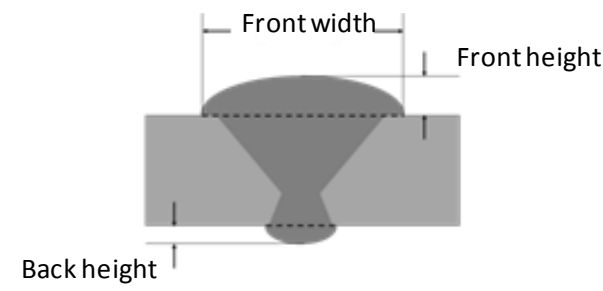

Figure 3. Weld bead linear geometric parameters.

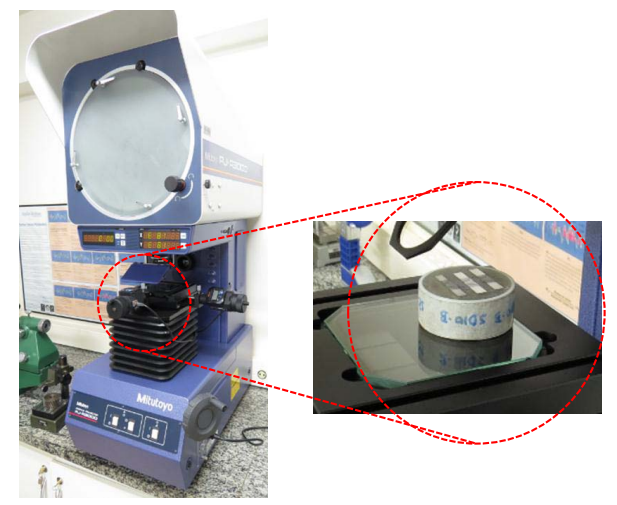

Figure 4. Specimens on measurement table of profile projector. 
This equipment allows measuring linear dimensions with a $0.001 \mathrm{~mm}$ resolution and angles with 1 minute resolution. The nominal range for linear dimensions is defined by the capacities of the axes $X$ and $Y$, as they are $50 \mathrm{~mm}$, while it is 360 degrees the measurement of angles.

The profile projector used, has a calibration certificate N. 12137/12 issued by the Mitutoyo Metrology Laboratory of South American. The expanded uncertainty associated with the magnifying lens calibration is $0.01 \%$ for $\mathrm{k}$ equals to 2.00 and infinite effective degrees of freedom. While the expanded uncertainty for length measurement is $0.002 \mathrm{~mm}$ for both axes, with $\mathrm{k}$ equal to 2.03 and 99 effective degrees of freedom.

During measurement, the samples were placed on the coordinates table as shown in Figure 3.

The measurements were carried out at a controlled room temperature of $(20 \pm 1)^{\circ} \mathrm{C}$ [9]. A thermo-hygrometer with a digital increment of $0.1^{\circ} \mathrm{C}$ and measurement range of $(-20 \text { to } 60)^{\circ} \mathrm{C}$ was used to monitor the temperature.This equipment has a calibration certificate N. R4996/13 issued by Elus Instrumentação Temperature and Humidity Laboratory. For temperature, the expanded uncertainty is $0.3^{\circ} \mathrm{C}$ for k equal to 2.00 and infinite degrees of freedom. All the instruments and parts used in the measurement tests were exposed to this temperature for approximately $12 \mathrm{~h}$ before the measurements. In order to remove dust or other dirt particles that could interfere with the measurement results, all the instruments and parts were cleaned using isopropyl alcohol, gloves, cotton buds and dry cloths.

The uncertainty evaluation associated with the front width measurement was performed as recommended by [10].

The influence factors considered for uncertainty evaluation were: variability of the readings indicated by profile projector; profile projector resolution; standard uncertainty associated with the profile projector calibration; uncertainty associated with lens increase; temperature variation during the measurements and the distance from the environment temperature to the reference temperature $\left(20^{\circ} \mathrm{C}\right)$.

Thus, the mathematical model is expressed according to Equation (1).

$$
\begin{aligned}
M= & \Delta s(L)+\Delta R_{P}+\Delta I_{P}+\Delta A_{P} \\
& +L_{0} \cdot \Delta T \cdot\left(\alpha_{P e}+\alpha_{P}\right)+L_{0} \cdot \delta T \cdot\left(\alpha_{P e}+\alpha_{P}\right)
\end{aligned}
$$

Wherein:

M: the measurement (front bead width);

$\Delta s(L)$ : correction due to standard deviation of the values indicated by the projector;

$\Delta R_{P}$ : correction due to the projector resolution;

$\Delta I_{P}$ : correction associated to the standard uncertainty of the projector calibration;
$\Delta A_{P}$ : correction associated to the projector lens increase;

$\delta T$ : temperature variation during measurements;

$\Delta T$ : distance from the environment temperature to the reference $\left(20^{\circ} \mathrm{C}\right)$;

$\alpha_{P}$ : linear thermal expansion coefficient of micrometer heads material (for linear dimensions);

$\alpha_{P e}$ : linear thermal expansion coefficient of the part material;

$L_{0}$ : average value of the measurement.

Therefore, the law of propagation of uncertainty must be applied to express the combined standard uncertainty as:

$$
\begin{aligned}
u_{c}^{2}(M) & =\left(\frac{\partial M}{\partial \Delta s L}\right)^{2} \cdot u^{2}(\Delta s L)+\left(\frac{\partial M}{\partial \Delta R_{P}}\right)^{2} \cdot u^{2}\left(\Delta R_{P}\right) \\
& +\left(\frac{\partial M}{\partial \Delta I_{P}}\right)^{2} \cdot u^{2}\left(\Delta I_{P}\right)+\left(\frac{\partial M}{\partial \Delta A_{P}}\right)^{2} \cdot u^{2}\left(\Delta A_{P}\right) \\
& +\left(\frac{\partial M}{\partial \Delta T}\right)^{2} \cdot u^{2}(\Delta T)+\left(\frac{\partial M}{\partial \delta T}\right)^{2} \cdot u^{2}(\delta T) \\
& +\left(\frac{\partial M}{\partial \alpha_{P e}}\right)^{2} \cdot u^{2}\left(\alpha_{P e}\right)+\left(\frac{\partial M}{\partial \alpha_{P}}\right)^{2} \cdot u^{2}\left(\alpha_{P}\right)
\end{aligned}
$$

The standard uncertainty related to $s(L)$ can be calculated as shown in Equation (3).

$$
u(\Delta s(L))=\frac{s}{\sqrt{n}}
$$

Where $s$ is the standard deviation of the measurement and $\mathrm{n}$ is the total number of measurement.

The correction due to the projector resolution is given by Equation (4).

$$
u(\Delta R)=\frac{R}{2 \cdot \sqrt{3}}
$$

The correction associated to the projector lens increase is given by Equation (5).

$$
u\left(\Delta A_{p}\right)=\frac{0.01 \%\left(L_{0}\right)}{k}
$$

The correction due to the uncertainty associated with the projector indication system is given by Equation (6).

$$
u\left(\Delta I_{p}\right)=\frac{U}{k}
$$

The correction due to difference between coefficients of thermal expansion of the scale and work piece is given by Equation (7).

Where $\alpha_{p}$ is the coefficient of thermal expansion of the scale of projector and $\alpha_{p e}$ is the coefficient of thermal expansion of the work piece.

$$
u(\Delta \alpha)=\frac{0.01\left(\alpha_{P}-\alpha_{E}\right)}{\sqrt{3}}
$$


Both variables related to room temperature variation were measured using the same measurement system. Therefore, they were treated as correlated. The correction due to the distancing of the temperature in relation to $20^{\circ} \mathrm{C}$ $\left(\Delta T_{20}\right)$ is determined using Equation (8).

$$
u\left(\Delta T_{20}\right)=\sqrt{\left(\frac{\Delta T}{\sqrt{3}}\right)^{2}+\left(\frac{\Delta R_{\mathrm{T}}}{2 \cdot \sqrt{3}}\right)^{2}+\left(\frac{\Delta I_{\mathrm{T}}}{k_{T}}\right)^{2}}
$$

Where $\Delta T$ is the difference between the room temperature and $20^{\circ} \mathrm{C} ; \Delta R_{T}$ is the correction in relation to the thermometer resolution and $\Delta I_{T}$ is the uncertainty associated with the thermometer indication system.

The uncertainty due to temperature variation during measurement is given by Equation (9).

$$
u(\Delta \delta T)=\sqrt{\left(\frac{\operatorname{Var}(T)}{\sqrt{3}}\right)^{2}+\left(\frac{\Delta R_{\mathrm{T}}}{2 \cdot \sqrt{3}}\right)^{2}+\left(\frac{\Delta I_{\mathrm{T}}}{k_{T}}\right)^{2}}
$$

\section{Results and Discussion}

Table 2 displays the mean $(\bar{x})$ and standard deviation (s) from the readings obtained while measuring front width with the profile projector for all weld beads.

Observing the measurement results shown in Table 2 and comparing each sample separately it may be noted that the overhead $(\mathrm{OH})$ produces the smallest front bead width. And, except for SD10 sample, the largest width is from vertical welding position (V). So, with a smaller width, the thermal deformation is smaller due to the reduced heat affected area and it consumes a smaller electrode quantity and weld volume.

Comparing the average result of the three samples (Table 3) it is concluded that the $\mathrm{OH}$ welding showed, under the conditions of this study, the smaller bead width $(8.055 \mathrm{~mm})$. And the vertical welding showed the largest width $(8.732 \mathrm{~mm})$. There was a lower repeatability of bead width in $\mathrm{OH}$, this can be due to the fact that in this position it is more difficult to do the welding.

Taking the average width for position $\mathrm{V}$ welding as reference, it can be said that the average width obtained

Table 2. Front width values for each weld bead.

\begin{tabular}{ccc}
\hline \multicolumn{3}{c}{ Front width for each weld bead $(\mathrm{mm})$} \\
\hline Weld bead & Mean $(\bar{x})$ & Standard deviation $(\mathrm{s})$ \\
\hline SD10-OH & 8.866 & 0.006 \\
SD11-OH & 7.607 & 0.030 \\
SD18-OH & 7.693 & 0.010 \\
SD10-V & 9.230 & 0.017 \\
SD11-V & 8.382 & 0.015 \\
SD18-V & 8.584 & 0.012 \\
SD10-F & 10.062 & 0.006 \\
SD11-F & 7.635 & 0.019 \\
SD18-F & 7.609 & 0.010 \\
\hline
\end{tabular}

in SC position is $7.75 \%$ lower, while in $\mathrm{F}$ position it was $3.40 \%$ lower.

The uncertainty associated to the measurement of the front width in overhead position to the specimen SD10 is displayed in Table 4. In this table E represents the estimated value of the input variable considered; TI, the type of standard uncertainty evaluation; DP, the probability distribution adopted and DF the number of degrees of freedom.

In Table 4 were added two significant figures to standard uncertainty values $(u)$, to combined standard uncertainty $\left(u_{c}\right)$ and to expanded uncertainty $(U)$ in order to reduce errors due to rounding. In all cases the sensitivity coefficient is equal to 1 .

It is observed in Table $\mathbf{4}$ that expanded uncertainty associated to the front width measurement obtained in overhead position for specimen SD10 is $0.016 \mathrm{~mm}$ for $\mathrm{k}$ equal to $4.30 \%$ and $95 \%$ coverage probability. Thus the values, which may be attributed to the measure and in this case, are in the range [8.866 $\mathrm{mm} \pm 0.016 \mathrm{~mm}$ ].

The variable that most contributed to final uncertainty was the variability of readings, with a contribution of approximately $89.86 \%$, followed by the uncertainty associated with the profile projector calibration, with $7.35 \%$.

The contribution of the variables, profile projector resolution and uncertainty associated to the magnifying lens, was very small, assuming values of $2.52 \%$ and $0.24 \%$, respectively.

Table 5 displays the results obtained during the evaluation of the uncertainty associated to the width measurement for all weld beads. This table shows the values of the effective degrees of freedom $\left(v_{\text {eff }}\right)$, the coverage factor $(k)$ and the expanded uncertainty $(U)$ in $\mathrm{mm}$. In all cases the probability of coverage was $95 \%$.

Table 3. Average results between the three samples by weld type.

\begin{tabular}{ccc}
\hline Type & Mean $(\bar{x})$ & Standard deviation (s) \\
\hline OH & 8.055 & 0.013 \\
V & 8.732 & 0.003 \\
F & 8.435 & 0.007 \\
\hline
\end{tabular}

Table 4. Uncertainty components to the SD10-OH speci-

\begin{tabular}{|c|c|c|c|c|c|}
\hline \multicolumn{6}{|c|}{ Uncertainty components } \\
\hline Quantity & $\mathrm{E}(\mathrm{mm})$ & $\mathrm{TI}$ & DP & DF & $\mathrm{u}(\mathrm{mm})$ \\
\hline$\Delta s\left(L_{p r}\right)$ & 0.006 & A & $\mathrm{N}$ & 2 & 0.00346 \\
\hline$\Delta R_{P r}$ & 0.001 & B & $\mathrm{R}$ & $\infty$ & 0.00058 \\
\hline$\Delta A_{P r}$ & 0.00044 & B & $\mathrm{N}$ & $\infty$ & 0.00018 \\
\hline$\Delta I_{P r}$ & 0.0009 & $\mathrm{~B}$ & $\mathrm{~N}$ & 99 & 0.00099 \\
\hline \multicolumn{5}{|c|}{ Combined standard uncertainty $\left(u_{c}\right)[\mathrm{mm}]$} & 0.00365 \\
\hline \multicolumn{5}{|c|}{ Effective degrees of freedom $\left(v_{\text {eff }}\right)$} & 2.47 \\
\hline \multicolumn{5}{|c|}{ Coverage factor $(k)$} & 4.30 \\
\hline \multicolumn{5}{|c|}{ Expanded uncertainty $(U)[\mathrm{mm}]$} & 0.01571 \\
\hline
\end{tabular}
men. 
Table 5. Uncertainty for all weld beads.

\begin{tabular}{cccc}
\hline \multicolumn{4}{c}{ Uncertainty for all weld beads } \\
\hline Weld Bead & $v_{\text {eff }}$ & $k$ & $U(\mathrm{~mm})$ \\
\hline SD10-OH & 2.47 & 4.30 & 0.016 \\
SD11-OH & 2.01 & 4.30 & 0.075 \\
SD18-OH & 2.16 & 4.30 & 0.026 \\
SD10-V & 2.06 & 4.30 & 0.043 \\
SD11-V & 2.07 & 4.30 & 0.038 \\
SD18-V & 2.11 & 4.30 & 0.031 \\
SD10-F & 2.47 & 4.30 & 0.016 \\
SD11-F & 2.04 & 4.30 & 0.048 \\
SD18-F & 2.16 & 4.30 & 0.026 \\
\hline
\end{tabular}

From Table 5 it follows that the expanded uncertainty values range between $0.016 \mathrm{~mm}$ and $0.075 \mathrm{~mm}$ for all measurements, indicating that the results are adequate considering the required accuracy for measuring the front bead width. The results obtained are suitable considering the required accuracy for measuring the front width.

The weld beads obtained at $\mathrm{OH}$ position have showed the highest values of expanded uncertainty, as well as the higher dispersion between them.

In all cases the variable that most contributed to the final uncertainty was the variability of the readings. This can be explained by the difficulties that the operator finds when setting the reference points for measuring the front width. Thus, the operator may be a significant source of error in this measurement. To minimize this effect, investments on the operator training must be done.

\section{Acknowledgements}

The authors are grateful to FAPEMIG/Brazil and CAPES/ PROEX for financial support.

\section{REFERENCES}

[1] Soldagem \& Brasagem, "Historia da Soldagem,” 2012. http://soldagemebrasagem.blogspot.com.br/2012_03_22_ archive.html

[2] P. J. Modenesi, P. V. Marques and D. B. Santos, "Introdução à Metalurgia da Soldagem,” Belo Horizonte, Brasil, 2012, p. 209.

http://demet.eng.ufmg.br/wp-content/uploads/2012/10/me talurgia.pdf

[3] A. R. Valdés, E. M. Díaz Cédre, A. C. Crespo and A. Piratelli-Filho, "Incerteza na Medição dos Parâmetros Geométricos do Cordão de Solda,” Soldagem e Inspeção, Vol. 16, No. 1, 2011, pp. 62-70. http://dx.doi.org/10.1590/S0104-92242011000100008

[4] Associação Brasileira de Normas Técnicas, NBR ISO/ IEC 17025: "Requisitos Gerais para Competência de Laboratório de Ensaios e Calibrações,” Rio de Janeiro, Brasil, 2005, p. 20.

[5] R. A. Valdés and J. R. S. Ribeiro, "Incerteza na Medição da Largura de Cordões de Solda,” Soldagem e Inspeção, Vol. 14, No. 3, 2009, pp. 263-269.

[6] C. M. D. Starling, P. J. Modenesi and T. M. D. Borba, "Caracterização do Cordão na Soldagem FCAW com um Arame Tubular ("MetalCored”)," Soldagem e Inspeção, São Paulo, Vol. 16, No. 3, 2011, pp. 285-300.

[7] R. A. Valdés, A. C. Crespo, A. Piratelli-Filho and E. M. Díaz Cedre, "Aplicación de Criterios Metrológicos a la Evaluacióndel Recargue por Soldadura,” São Luís, Maranhão, Brasil, CONEM, 2012, p. 10.

[8] J. S. Kim, L. S. Kim, J. H. Lee and S. M. Jung, “An Experimental Study on the Prediction of Back-Bead Geometry in Pipeline Using the GMA Welding Process," International Scientific Journal, Vol. 49, No. 1, 2011, pp. 5361.

[9] Associação Brasileira de Normas Técnicas, NBR NMISO 1: "Temperatura Padrão de Referência para Medições Industriais de Comprimento,” Rio de Janeiro, Brasil, 1997, p. 2.

[10] ISO TAG 4/WG 3, "Guide to the Expression of Uncertainty in Measurement," Geneva, Switzerland, 2008, p. 131. 